University of Nebraska - Lincoln

DigitalCommons@University of Nebraska - Lincoln

USDA National Wildlife Research Center - Staff

Publications

U.S. Department of Agriculture: Animal and Plant Health Inspection Service

$2-21-2006$

\title{
Efficacy of Scent Dogs in Detecting Black-Footed Ferrets at a Reintroduction Site in South Dakota
}

Sara A. Reindl-Thompson

United States Fish and Wildlife Service

John A. Shivik

Utah State University, Logan, UT

Alice Whitelaw

Working Dogs for Conservation Foundation

Aimee Hurt

Working Dogs for Conservation Foundation

Kenneth F. Higgins

South Dakota State University, kenneth.higgins@sdstate.edu

Follow this and additional works at: https://digitalcommons.unl.edu/icwdm_usdanwrc

Part of the Environmental Sciences Commons

Reindl-Thompson, Sara A.; Shivik, John A.; Whitelaw, Alice; Hurt, Aimee; and Higgins, Kenneth F., "Efficacy of Scent Dogs in Detecting Black-Footed Ferrets at a Reintroduction Site in South Dakota" (2006). USDA National Wildlife Research Center - Staff Publications. 438.

https://digitalcommons.unl.edu/icwdm_usdanwrc/438

This Article is brought to you for free and open access by the U.S. Department of Agriculture: Animal and Plant Health Inspection Service at DigitalCommons@University of Nebraska - Lincoln. It has been accepted for inclusion in USDA National Wildlife Research Center - Staff Publications by an authorized administrator of DigitalCommons@University of Nebraska - Lincoln. 


\title{
Efficacy of Scent Dogs in Detecting Black-Footed Ferrets at a Reintroduction Site in South Dakota
}

\author{
SARA A. REINDL-THOMPSON, ${ }^{1}$ United States Fish and Wildlife Service, Pierre, SD 57501, USA \\ JOHN A. SHIVIK, ${ }^{2}$ United States Department of Agriculture, Wildlife Services National Wildlife Research Center, and Department of Wildland \\ Resources, Utah State University, Logan, UT 84322, USA \\ ALICE WHITELAW, Working Dogs for Conservation Foundation, Three Forks, MT 59792, USA \\ AIMEE HURT, Working Dogs for Conservation Foundation, Three Forks, MT 59792, USA \\ KENNETH F. HIGGINS, United States Geological Survey, South Dakota Cooperative Fish and Wildlife Research Unit, South Dakota State \\ University, Brookings, SD 57007, USA
}

\begin{abstract}
Endangered black-footed ferrets (Mustela nigripes) are difficult to monitor because of their nocturnal and fossorial habits, but land use and management are influenced by their potential presence. Detector dogs have been suggested as a method for determining ferret presence, although its efficacy has not been thoroughly investigated. We evaluated 2 dogs trained specifically for determining ferret presence in field evaluations conducted in black-tailed prairie dog (Cynomys ludovicianus) colonies at the Conata Basin reintroduction site in South Dakota, USA, during September and October 2003. We tested the dogs on 4 test colonies that had no record of ferret presence and 7 colonies known to have ferrets inhabiting them. One dog was $100 \%$ accurate at detecting presence and the other was between $57 \%$ and $71 \%$ successful at detecting ferrets, with neither dog falsely indicating presence when ferrets were absent. For the 2 dogs, the mean time to detect ferrets on a prairie dog colony was 21 minutes and mean search rate was 26 ha/hour. The mean time to detection on the same sites was 208 minutes for spotlight surveys and mean search rate was 1.6 ha/ hour. Although spotlight surveys are necessary for identifying population demographics, well-trained detection dogs show promise for detecting ferret presence in prairie dog colonies. (WILDLIFE SOCIETY BULLETIN 34(5):1435-1439; 2006)
\end{abstract}

\section{Key words}

black-footed ferret, detection dog, Mustela nigripes, scent dog, spotlight survey.

The black-footed ferret (Mustela nigripes), once believed to be extinct, was rediscovered in 1982 near Meeteetse, Wyoming, USA. Successful captive propagation of this population yielded enough ferrets to make reintroductions possible (Forest et al. 1988, Miller et al. 1996). Currently 9 ferret reintroduction sites exist in North America, ranging from north-central Montana, USA, and central South Dakota, USA, to northern Mexico. All of the reintroduction sites occur on active prairie dog (Cynomys spp.) colonies.

Federal, state, and tribal entities currently manage and monitor ferret reintroduction sites to detect trends or dramatic changes in ferret populations. These efforts are impeded by the lack of suitable monitoring techniques given the secretive nocturnal habits of the animals (Clark et al. 1986). Spotlight surveys of ferrets currently are the preferred method for gathering information on individuals and population demographics. However, demographic information is not always essential. Because the species is federally listed as endangered, land use and management may be influenced by the presence (or potential presence) of ferrets. Therefore, an efficient tool for detecting ferret presence on wide swaths of lands is needed. Scent stations (Hammer and Anderson 1985), video cameras triggered by an infrared sensor (Hinckley and Crawford 1973), night-vision goggles

1 Present address: United States Department of Agriculture, Natural Resources Conservation Service, Huron, SD 57350, USA

2 E-mail: john.shivik@aphis.usda.gov and scopes (Martin and Schroeder 1980), and scentdetection dogs (Southwest Research Institute 1979) have been tried. Many of these methods did not work, their high costs prohibited wide-scale use, or the field application of the method was not fully developed, as was the case with scent-detection dogs.

Several authors have described dog use and efficiency in field research or identified means of improving dog use by reducing biases or enhancing their capabilities (Zwickel 1980, Gutzwiller 1990, Homan et al. 2001, Shivik 2002, Smith et al. 2003). In 2001 a scent-detection dog was trained to find black-footed ferret scat and used in trials at a reintroduction site on the Charles M. Russell National Wildlife Refuge in Montana (M. R. Matchett, Charles M. Russell National Wildlife Refuge, personal communication). The results of this trial were promising and justified further evaluation of scent dogs for detecting ferrets in a natural environment. The objective of our research was to determine the accuracy and efficiency of dogs specially trained to detect the presence of ferrets on prairie dog colonies.

\section{Study Area}

Black-footed ferrets were introduced during 1996-1999 to the Conata Basin site, which was located in the Buffalo Gap National Grasslands near Wall, South Dakota. These grasslands encompassed approximately $2,430 \mathrm{~km}^{2}$ in the semiarid portion of southwestern South Dakota (United States Forest Service 1995). Mean temperatures in the area 
ranged from $-4.6^{\circ} \mathrm{C}$ in the winter to $25.5^{\circ} \mathrm{C}$ in the summer. Average annual precipitation was $39.9 \mathrm{~cm}$, most of which came as rain during the growing season (Severson and Plumb 1998). Badlands formations characterized the Conata Basin area. The soils of the area were primarily composed of clay. Vegetation was dominated by blue grama (Bouteloua gracilis), buffalograss (Buchloe dactyloides), western wheatgrass (Agropyron smithii), upland sedges (Carex spp.), red three-awn (Aristida purpurea), scarlet globemallow (Sphaeralcea coccinea), wooly Indian wheat (Plantago patagonica), and plains prickly pear (Opuntia polyacantha; MacCracken et al. 1985).

The Conata Basin ferret reintroduction site was bordered by Badlands National Park to the west, east, and north. The United States Forest Service currently manages the grasslands by allotting grazing permits to local ranchers. Cattle have grazed on the grasslands since 1900 (MacCracken et al. 1985). This study was conducted entirely within the Wall Ranger District of the Buffalo Gap National Grasslands.

Black-tailed prairie dogs (Cynomys ludovicianus) currently inhabit $60 \mathrm{~km}^{2}$ within the $315-\mathrm{km}^{2}$ reintroduction area and their density was estimated at 30 prairie dogs/ha (Perry 2004). Ferrets were released in the Conata Basin site from 1996 through 1999, and the subsequent litter production in the wild has produced a growing population estimated at nearly 300 animals during autumn 2003 (Perry 2004). Ferret monitoring is intensive on the site, with field crews annually conducting spotlight surveys from late July until February (as weather and budget permit). Snow-tracking surveys are conducted when conditions allow.

Eleven prairie dog colonies, termed test colonies, were separated into 2 categories: 7 colonies with ferret presence and 4 without ferret presence. Test colonies designated as having no ferrets were separated from those with ferrets by a wall of badlands formations and other landscape features that would make ferret movement between these areas during the trials highly improbable. Test colonies were of similar sizes, averaging 27 ha (range 8-38 ha), and were spatially distinct, except for test colonies 1 and 2, which were a single 54-ha colony divided into 2 equally sized areas for testing.

\section{Methods}

\section{Scent-Dog Training}

Dog training and search protocols for this study were developed by dog handlers from Working Dogs for Conservation, Bozeman, Montana. The training program incorporated a combination of training protocols used by narcotics, search and rescue, and cadaver dog trainers. The dogs initially were trained to indicate the presence of ferret scat obtained from a captive animal. However, the goal of this training was to indicate presence of ferrets and not location of scats. Therefore, training also included odor sources, such as bedding and a live black-footed ferret in a holding tube. For example, in one exercise 4 tubes were placed for the dog to examine: one with a live prairie dog, one with a prairie-dog-scented article, one with a live ferret, and one blank tube. The dog was rewarded when the correct tube was approached, reinforcing the connection between ferret scat and live ferret. In later sessions, ferret scat and the live ferret in the holding tube were alternately put in the lineup to reinforce that both scents represented a reward for the dog. By presenting the dog with both types of scent material and rewarding the dog for detecting both, a connection between scat and actual ferret scent was thought to have been made by the dog so that it recognized "ferret," not just ferret scat. During the course of training, blind and double-blind trials were frequently employed to gauge progress and capability of the dogs before they were assessed in the experiment described in this paper (see Reindl 2004).

\section{Scent-Dog Evaluation}

Two handlers from Working Dogs for Conservation (Bozeman, Montana) developed and followed dog training and search protocols for this study (Reindl 2004). We incorporated a disease-prevention protocol approved by the United States Fish and Wildlife Service (USFWS) Ferret Conservation Center, Sybille, Wyoming, to minimize plague, rabies, and canine distemper transmission. In addition, all research activities were reviewed and approved by the United States Department of Agriculture Wildlife Services National Wildlife Research Center's Institutional Animal Care and Use Committee (QA 1066). We randomly assigned the order in which each handler-dog team searched the numbered test colonies and gave the handlers no information on the test colonies other than the size of the colony to search. Teams worked separately from each other, were not allowed to discuss any aspects of the trials until the end of the study, and handlers were blind to experimental treatments until the conclusion of the study. If 2 teams drew the same colony to search on a given day, they could work the same colony on the same day, but not at the same time. The second team to work the area was not allowed to watch the first team.

To provide a baseline measurement of effort and efficiency, we conducted spotlight surveys for 3 consecutive nights on each colony (Forrest et al. 1988, USFWS 1989) within a 2-week period that encompassed the dog trials. We assessed relative efficiency of dogs and searchlight methods using latency to detect ferrets (when ferrets were present). Our metric of concern was not variability in dog ability or human searcher; therefore, individual colonies were sample units used to conduct our analyses. We determined relative speed (search time per hectare) and time to detection for each method by measuring the time to complete a search of each colony, and assessed differences using paired-samples $t$-tests. We conducted field evaluations in 2 sessions, from 15-18 September and from 16-29 October 2003. We analyzed data as first-time searches of test colonies and second-time searches of test colonies to account for possible site recognition in second searches. 
Table 1. Search results for dog 1 and dog 2 during first searches conducted at the Conata Basin, South Dakota, USA, black-footed ferret reintroduction site during 15-28 Sep 2003.

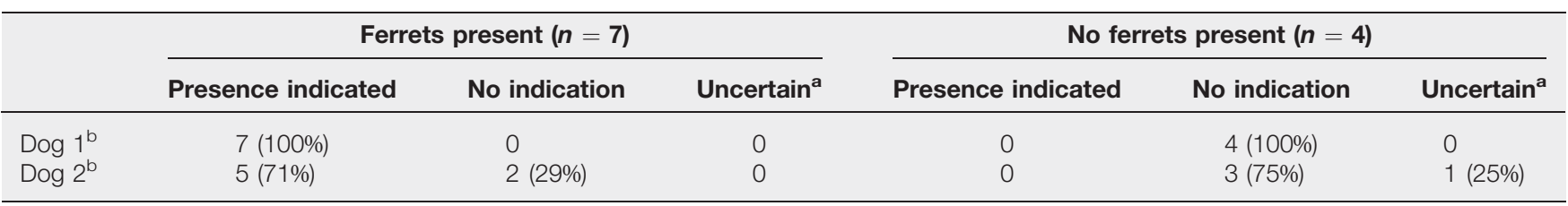

a "Uncertain" was recorded for colonies for which either the dog gave ambiguous alerts or the handler did not feel the dog was working well.

${ }^{b}$ Dogs 1 and 2 were blind-tested on 11 prairie dog colonies: 7 had resident ferrets and 4 had no record of ferret presence.

\section{Results}

Overall, first-time searches of test colonies by dog teams resulted in correctly determining ferret presence in $86 \%$ of colonies and absence in $88 \%$ of colonies (Table 1). Secondtime searches of the same test colonies yielded a correct assessment of ferret presence in 79\% of occasions and ferret absence in $88 \%$ of occasions (Table 2). We never observed a trial in which dogs falsely indicated the presence of ferrets.

During these trials, spotlighting always correctly detected ferret presence and correctly indicated ferret absence. Time to first detection for dogs $(\bar{x}=21 \mathrm{~min}, \mathrm{SE}=3.1)$ was faster $\left(T_{6}=2.63, P=0.04\right.$; Table 3$)$ than spotlight surveyors $(\bar{x}=$ $207.9 \mathrm{~min}, \mathrm{SE}=71.0)$. Furthermore, dogs also were much faster $\left(T_{10}=8.9, P<0.001\right)$ at searching colonies $(\bar{x}=25.9$ $\mathrm{ha} / \mathrm{hr}, \mathrm{SE}=2.7)$ than spotlight surveyors $(\bar{x}=1.6 \mathrm{ha} / \mathrm{hr}, \mathrm{SE}$ $=0.2$; Table 3 )

\section{Discussion}

\section{Method Comparison}

Our spotlighting surveys were 100\% accurate for ferret presence determination, but required more search time to first detection than detection dogs. Dogs were faster but at the cost of having more error associated with their use. Based on our study results and observations, acknowledging that only recently have dogs been trained for ferret detection and noting that one dog was $100 \%$ correct in detecting ferrets, we believe a high detection accuracy for professionally trained dogs could be achieved.

Also, additional anecdotal information indicated that dogs can find ferrets when spotlight surveys do not. Indeed, some ferrets are never seen despite intensive spotlighting efforts, and their presence needs to be confirmed through other means such as snow-tracking (Richardson et al. 1985; M. R. Matchett, personal communication). During training exercises near the study site, dogs searched 2 prairie dog colonies that had never before been searched for ferret presence. In this double-blind trial, both dogs searched 2 100-ha colonies once. The dogs indicated ferret presence on one colony and no ferret presence on the other. A United States Forest Service crew subsequently conducted spotlight surveys on the colonies for 2 nights, but did not observe ferrets. In an effort to confirm ferret presence as indicated by the dogs, we set traps where one of the dogs indicated ferret presence and an adult male ferret was trapped there that night. This anecdotal information further indicates that dogs can provide a useful auxiliary method for determining the presence of ferrets.

Our study was designed to evaluate efficiency of detection dogs for identifying the presence or absence of ferrets; however, cost also is an important consideration. As techniques are refined and made more efficient, costs may vary, but currently, contracting a trained dog-and-handler team can cost approximately US $\$ 400$ per day. Depending on the type and intensity of the search, most detection dogs can work approximately 4 hours per day. We found that scent dogs were able to cover an average of 26 ha/hour. The cost for dogs in this study was $\$ 3.85 / \mathrm{ha}$ based on each $\operatorname{dog}$ working an average of $26 \mathrm{ha} / \mathrm{hour}$ at $\$ 400 / 4$-hour day. These estimates are approximate and not necessarily accurate for use in forming a ferret monitoring program or for comparison to other methods, but cost-per-hectare data suggest that using scent-detection dogs is economically comparable to the most common ferret monitoring method.

Spotlighting has additional benefits because it enables observation and recognition of individual ferrets for population analyses, beyond the limited presence-absence indication that dogs provide. However, additional benefits of using dogs include potential for finding scat, and physical evidence of ferrets is seldom found using other methods. Furthermore, dog teams are minimally invasive and can search areas where vehicles cannot travel due to rough terrain. Ultimately, choice of which method to use will be an

Table 2. Search results for dog 1 and dog 2 during second searches conducted at the Conata Basin, South Dakota, USA, black-footed ferret reintroduction during 16-29 Oct 2003.

\begin{tabular}{|c|c|c|c|c|c|c|}
\hline & \multicolumn{3}{|c|}{ Ferrets present $(n=7)$} & \multicolumn{3}{|c|}{ No ferrets present $(n=4)$} \\
\hline & Presence indicated & No indication & Uncertain $^{a}$ & Presence indicated & No indication & Uncertain $^{\mathrm{a}}$ \\
\hline $\operatorname{Dog} 1^{\mathrm{b}}$ & $7(100 \%)$ & 0 & 0 & 0 & $3(75 \%)$ & $1(25 \%)$ \\
\hline $\operatorname{Dog} 2^{b}$ & $4(57 \%)$ & $3(43 \%)$ & 0 & 0 & $4(100 \%)$ & 0 \\
\hline
\end{tabular}

a "Uncertain" was recorded for colonies for which either the dog gave ambiguous alerts or the handler did not feel the dog was working well.

${ }^{b}$ Dogs 1 and 2 were blind-tested on 11 prairie dog colonies: 7 had resident ferrets and 4 had no record of ferret presence. 
Table 3. Comparison of detection dog and spotlighting search times on 11 test colonies for detecting black-footed ferrets at Conata Basin, South Dakota, USA, from Sep-Oct 2003.

\begin{tabular}{|c|c|c|c|c|c|}
\hline \multirow[b]{2}{*}{ Test colony } & \multirow[b]{2}{*}{ Size (ha) } & \multicolumn{2}{|c|}{ Time to first detection (min) } & \multicolumn{2}{|c|}{ Search rate $(\mathrm{ha} / \mathrm{hr})$} \\
\hline & & Spotlighting & Dogs & Spotlighting & Dogs \\
\hline 1 & 27 & 15 & 28 & 1.5 & 28.7 \\
\hline 2 & 27 & 15 & 16 & 1.5 & 31.2 \\
\hline 3 & 29 & 90 & 18 & 1.0 & 22.0 \\
\hline 4 & 30 & 300 & 19 & 1.2 & 33.0 \\
\hline 5 & 13 & 150 & 32 & 1.5 & 10.7 \\
\hline 6 & 33 & 420 & 27 & 1.3 & 18.6 \\
\hline 7 & 38 & 465 & 8 & 1.3 & 23.0 \\
\hline 8 & 31 & na & na & 3.0 & 32.1 \\
\hline 9 & 31 & na & na & 2.9 & 40.9 \\
\hline 10 & 31 & na & na & 1.7 & 31.0 \\
\hline 11 & 8 & na & na & 1.1 & 14.1 \\
\hline
\end{tabular}

optimization process based on time, money, site conditions, and need for accuracy and additional information about ferrets on prairie dog colonies.

\section{Considerations When Working With Dogs}

There were several unforeseen problems that occurred while using dogs at the reintroduction site. Prairie dogs, for example, often distracted the detection dogs with their frequent barking and movement when the dogs were in close proximity, sometimes within $<2 \mathrm{~m}$ of their burrows. Also, because rattlesnakes (Crotalus spp.) frequently bask in burrow entrances, snakes presented potential injury to the dogs that investigated burrows by putting their noses down into entrances. Beds of prickly pear cactus (Opuntia spp.) and pincushions (Coryphantha spp.) caused some difficulty in movement over the colonies, and some areas may require use of protective boots for the dogs. If scent-detection dogs are used at other reintroduction sites, a period of acclimation, which includes sufficient time to detect and solve potential problems (e.g., dogs can be trained to ignore barking prairie dogs), should be undertaken prior to searching. Seasonal timing of searches also could prove critical to efficiency and accuracy of a search. In autumn when temperatures are cooler and ferret litters are dispersing, dog stamina and capability may be more optimal than during summer.

One of the most difficult issues trainers encountered was that handlers could not perceive what dogs perceive, especially when scents detected were from below-ground sources. Other scents (e.g., of prairie dogs) are ubiquitous and abundant. Thus, appropriate reinforcement in field training is as much an art as a science and should be accomplished by competent dog trainers, include intermittent training that reinforces ferret scent, discourages false alerts, and constantly monitors dog accuracy. Dogs are certainly capable of the task, but the importance of using properly trained and tested detection dogs and professional handlers cannot be overstated.

\section{Management Implications}

Scent-detection dogs can provide managers an additional method for monitoring populations of ferrets on reintroduction sites. If only presence or absence data are needed over large areas, detection dogs may be very useful, but dogs are especially well suited in remote areas not accessible by motor vehicles. Sites with the following situations probably would benefit the most from using detection dogs: limited personnel, rough topography, limited access, and limited time for monitoring efforts. When more information is needed about the population, such as sex and age ratios, reproduction rates, locations of litters, and individual identification, detection dogs are insufficient and other more invasive methods are required. Our results were specific to using 2 dogs in the Conata Basin environment, and using differentially experienced or qualified detection dogs at another site could affect efficiency and accuracy. Because of potential variability in dogs and their training, managers should be cautious when choosing handlers to employ.

\section{Acknowledgments}

We thank C. Dieter for reviewing an earlier draft of this paper and G. Larson for his reviews and support during the study. R. Matchett's review was very instrumental for clarifying and improving the paper. R. Powell's comments, thoughts, and grammatical lessons were also extremely important. Working Dogs for Conservation provided trained dogs for the project. A. Clark of the Black-Footed Ferret Foundation provided funding for this project. P. Gober of the United States Fish and Wildlife Service and W. Perry of the Buffalo Gap National Grasslands Wall Ranger District provided equipment and staff for much of the field work. T. Livieri of Prairie Wildlife Research, Inc. provided assistance in data collection and processing. P. Marinari, T. Rodriguez, and personnel from the Henry Doorly Zoo provided the training materials. Black-footed Ferret Conservation Center and Denver Zoological Foundation provided logistical assistance. K. Bly-Honness, C. Maddox, and J. Reindl helped with data collection. 


\section{Literature Cited}

Clark, T. W., L. Richardson, S. G. Forrest, D. E. Casey, and T. M. Campbell III. 1986. Descriptive ethology and activity patterns of black-footed ferrets. Great Basin Naturalist Memoirs 8:115-134.

Forrest, S. C., D. E. Biggins, L. Richardson, T. W. Clark, T. M. Campbell III, D. A. Fagerstone, and E. T. Thorne. 1988. Population attributes for the black-footed ferret (Mustela nigripes) at Meeteetse, Wyoming, 1981-1985. Journal of Mammalogy 69:261-273.

Gutzwiller, K. J. 1990. Minimizing dog-induced biases in game bird research. Wildlife Society Bulletin 18:351-356.

Hammer, D. A., and S. H. Anderson. 1985. Using scent attractants as a technique to locate black-footed ferrets. Pages 26.1-26.12 in S. Anderson and D. Inkley, editors. Proceedings of a black-footed ferret workshop, 18-19 September 1984, Laramie, Wyoming, USA. Wyoming Game and Fish Department Publication, Cheyenne, USA.

Hinckley, D. D., and J. E. Crawford. 1973. Ferret and prairie dog programs on the national resource lands. Pages 133-135 in R.L. Linder and C. N. Hillman, editors. Proceedings black-footed ferret and prairie dog workshop, 2-4 September 1973, South Dakota State University, Brookings, USA.

Homan, H. J., G. Linz, and B. D. Peer. 2001. Dogs increase recovery of passerine carcasses in dense vegetation. Wildlife Society Bulletin 29: 292-296.

MacCracken, J. G., D. W. Uresk, and R. M. Hansen. 1985. Vegetation and soils of burrowing owl nest sites in Conata Basin, South Dakota. Condor 87:152-154.

Martin, S. J., and M. H. Schroeder. 1980. Black-footed ferret surveys on seven coal occurrence areas in Wyoming. U.S. Fish and Wildlife Service Ferret Report 2, Denver, Colorado, USA.

Miller, B., R. P. Reading, and S. Forrest. 1996. Prairie night: blackfooted ferrets and the recovery of endangered species. Smithsonian Institution, Washington, D.C., USA.

Perry, B. 2004. Unpublished annual report to black-footed ferret recovery team conservation subcommittee. Fort Collins, Colorado, USA.

Reindl, S. A. 2004. Efficacy of scent dogs in detecting black-footed ferrets (Mustela nigripes) at a reintroduction site in South Dakota. Thesis, South Dakota State University, Brookings, USA.

Richardson, L., T. W. Clark, S. C. Forrest, and T. M. Campbell III. 1985. Snow-tracking as a method to search for and study the black-footed ferret. Pages 25.1-25.11 in S. H. Anderson and D. B. Inkley, editors. Proceedings of a workshop on black-footed ferrets, 18-19 September 1984, Laramie, Wyoming, USA. Wyoming Game and Fish Department Publication, Cheyenne, USA.

Severson, K. E., and G. E. Plumb. 1998. Comparison of methods to estimate population densities of black-tailed prairie dogs. Wildlife Society Bulletin 26:859-866.

Shivik, J. A. 2002. Odor-adsorptive clothing, environmental factors, and search-dog ability. Wildlife Society Bulletin 30:721-727.

Smith, D. A., K. Ralls, A. Hurt, B. Adams, M. Parker, B. Davenport, M. C. Smith, and J. E. Maldonado. 2003. Detection and accuracy rates of dogs trained to find scats of San Joaquin kit foxes (Vulpes macrotis mutica). Animal Conservation 6:339-346.

Southwest Research Institute. 1979. Training of dogs to detect blackfooted ferrets. Southwest Research Institute Project Report 14-5331, San Antonio, Texas, USA.

United States Fish and Wildlife Service. 1989. Recommended criteria and procedures for black-footed ferret surveys. U.S. Fish and Wildlife Service Office of Endangered Species, Region 6, Denver, Colorado, USA.

United States Forest Service. 1995. Buffalo Gap National Grassland grasses. U.S. Department of Agriculture, Forest Service, Washington, D.C., USA.

Zwickel, F. C. 1980. Use of dogs in wildlife biology. Pages 531-536 in S. D. Schemnitz, editor. Wildlife management techniques manual. Fourth edition. The Wildlife Society, Washington, D.C., USA.

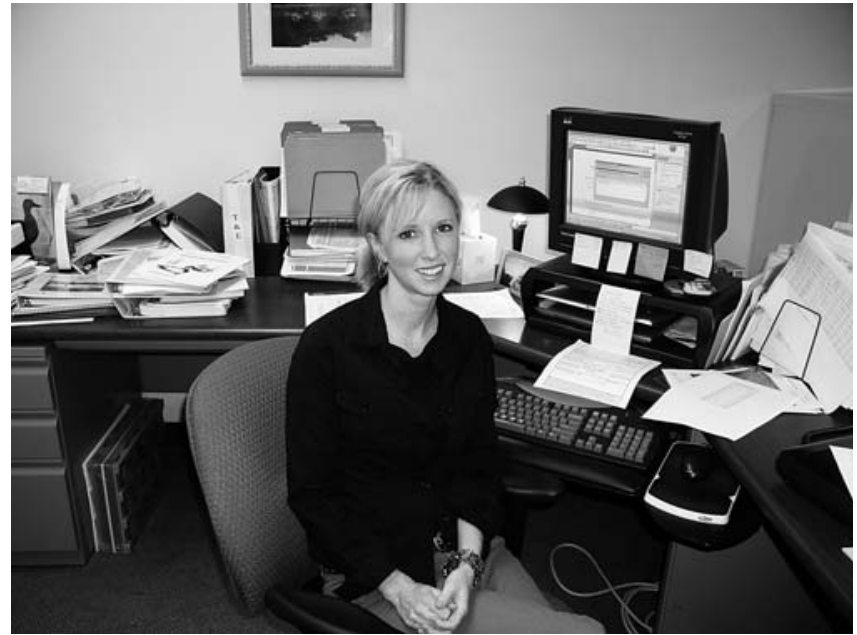

Sara A. Reindl-Thompson (photo) currently works for the United States Department of Agriculture (USDA) Natural Resources Conservation Service. While conducting this research, she was employed by the United States Fish and Wildlife Service. She has a B.S. and an M.S. in biology from South Dakota State University. She remains active in the arena of using detection dogs for conservation. John A. Shivik is the leader of the USDA, Wildlife Services, National Wildlife Research Center Logan Field Station and is an associate professor in the Department of Wildland Resources at Utah State University. He received his B.S. from Frostburg State University (1990), M.S. from the University of California at Berkeley (1995), and Ph.D. from Colorado State University (1999). His current research goals include using studies of animal behavior to help develop new tools and techniques for wildlife managers. Alice Whitelaw is a cofounder of Working Dogs for Conservation Foundation. She received a B.A. in biology from Warren Wilson College in North Carolina and an A.A.Sc. in Veterinary Medical Technology from Central Carolina Community College. She has worked as a field biologist for universities, nongovernmental organizations, and state and federal agencies for over 18 years and has participated in wildlife research throughout the United States, Mexico, Canada, and Russia. She has been involved in dog training for 21 years and has focused on the use of detection dogs for wildlife conservation since 1998. Aimee Hurt is a co-founder of Working Dogs for Conservation Foundation. She received a B.A. from the University of Montana in biology. She has worked on search techniques for a number of species in her 9 years of handling and training dogs. Her professional interests include understanding the potential and limitations of canine olfaction, perfecting laboratory discrimination experiments on various scents, and ensuring that dog-handler teams remain highly trained. Kenneth F. (Ken) Higgins is a retired assistant leader, professor, and wildlife research biologist of the United States Geological Survey Cooperative Fish and Wildlife Research Unit at South Dakota State University (SDSU). He received a Ph.D. from North Dakota State University in 1981, an M.S. from SDSU in 1968, and a B.S. from Colorado State University in 1965. He is past-president of the North and South Dakota chapters and the Central Mountains and Plains Section of The Wildlife Society. He retired in January 2006 after 40+ years of federal (United States Department of the Interior) service; he is currently working to complete 3 books for publication.

Associate Editor: McCleery. 